\section{Revista Brasileira de Cineantropometria e Desempenho Humano: trajetória e perspectivas}

\section{Brazilian Journal of Kinanthropometry and Human Performance: trajectory and perspectives}

Diego Augusto Santos Silva

Edio Luiz Petroski

O ano de 2014 se inicia e é com grande satisfação que a Revista Brasileira de Cineantropometria \& Desempenho Humano (RBCDH) entra em seu $16^{\circ}$ volume. Nessa trajetória, muitos foram os caminhos percorridos, às vezes tortuosos, e muitos foram os obstáculos ultrapassados, porém, bastante ainda há por fazer para tentar alcançar um número cada vez maior de pessoas em uma área que está em constante crescimento, como a Educação Física.

Após os 15 anos de história, algumas lições foram aprendidas as quais servirão para traçar planos para, quem sabe, os próximos 15 anos. Porém, à medida que o tempo passa as perspectivas e os sonhos também aumentam e, para tanto, faz-se necessário traçar objetivos plausíveis para o alcance de um maior número de leitores.

O objetivo desse editorial é informar algumas curiosidades desse caminho percorrido e fazer uma perspectiva concreta para o ano de 2014, trazendo dados da $\mathrm{RBCDH}$ durante a sua trajetória.

Esse tópico poderia iniciar com informações acerca de 1999 quando foi publicado o $1^{\circ}$ volume da RBCDH. Naquele ano, foi publicado somente um número da recém-criada revista. Entretanto, preferiu-se iniciar esse tópico com a informação mais recente sobre a RBCDH, que foi a incorporação na base da Thomson Reuters (ISI - Web of Knowledge), uma das mais respeitadas bases científicas. A incorporação no ISI aumenta as chances da revista ser lida e citada por um maior número de pesquisadores ao redor do mundo, o que pode aumentar o fator de impacto do periódico e a visibilidade dos autores que nela publicam. Além disso, muitas agências de fomento ao redor do mundo avaliam os pesquisadores por meio do impacto/visibilidade de suas pesquisas. Tal visibilidade está associada, na maior parte das vezes, com o fator de impacto do periódico que o artigo foi publicado. O fator de impacto gerado pela base Thomson Reuters (ISI - Web of Knowledge) é o que mais se considera em grande parte das agências de fomento ao redor do mundo.

Além da base supracitada, a RBCDH também se encontra nas seguintes, e não menos importantes, bases de indexação: DOAJ, LATINDEX, LILACS, LivRe, Portal de periódicos CAPES, SCImago, Scielo, Sportdiscus, SCOPUS, SEER.

Uma curiosidade em relação à trajetória da $\mathrm{RBCDH}$ é que, no primeiro volume, foram publicados 11 artigos, sendo 10 originais e 01 de revisão. editorial 
A maior dificuldade naquela época era a pouca quantidade de artigos submetidos para a revista. Com o passar dos volumes, e a maior quantidade de pesquisas desenvolvidas na área de Educação Física, aumentou a quantidade de números e artigos publicados pela RBCDH, por essa razão, a revista passou por algumas mudanças. De 1999 a 2002, a periodicidade dos números era anual; de 2003 a 2005, passaram a ser publicados dois números por ano; de 2006 a 2009, a periodicidade da publicação era trimestral, e desde 2010 a RBCDH publica seis números por volume.

Na Figura 1, pode-se observar a quantidade de artigos publicados a cada ano, incluindo-se os originais, de revisão e os pontos de vista. Até o final do ano de 2013, foram publicados 634 artigos. Ocorreu um aumento considerável na quantidade de pesquisas publicadas. Nós entendemos que o aumento na quantidade de Programas de Pós-Graduação em nível de mestrado e doutorado, o aumento na quantidade de pesquisas financiadas e o intercâmbio entre pesquisadores do Brasil e de outros países estimulados pelas agências brasileiras de fomento é uma das razões para maior quantidade de artigos publicados.

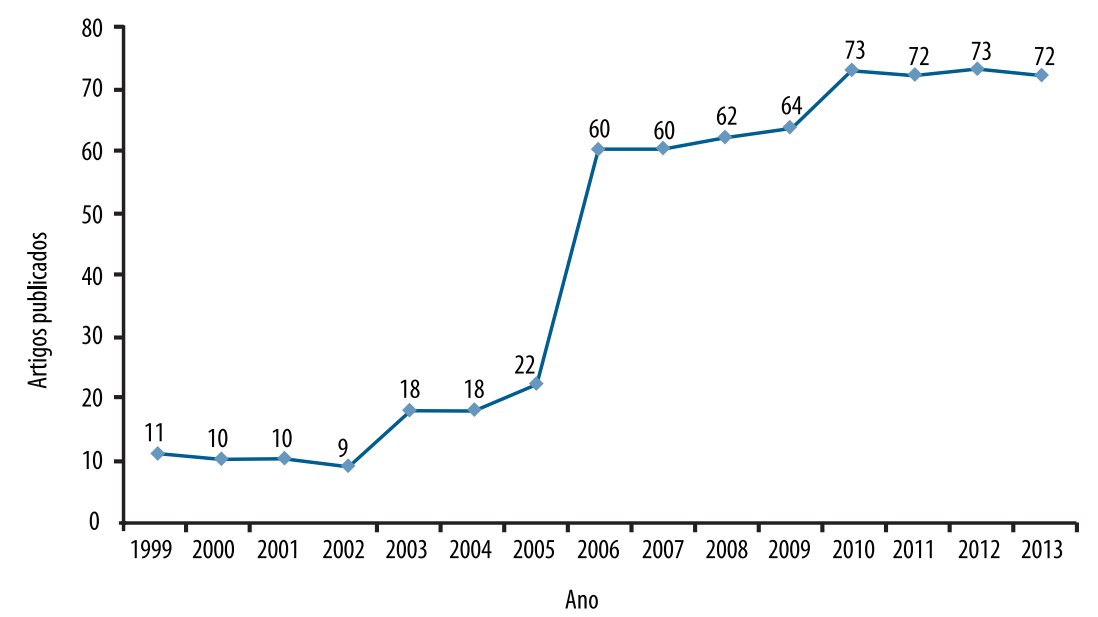

Figura 1. Número de artigos publicados na RBCDH de 1999 até 2013.

Na Figura 2, observa-se a razão de artigos submetidos/publicados a partir de 2006, quando se iniciou o processo de armazenar a informação da quantidade de artigos enviados à revista. Em 2006, a razão de artigos submetidos/publicados foi de 2,8, próximo ao que foi encontrado em 2013. Porém, em 2013, foram publicados mais artigos que em 2006. Ou seja, em 2013, a cada quase 3 artigos submetidos 1 era publicado. Em 2011 e 2012, foram os anos com maior razão de artigos submetidos/publicados, possivelmente, devido à inserção da RBCDH na base de dados Scielo e automaticamente, na maior qualificação da revista perante o Qualis Capes da área 21 (B1).

Na Tabela 1, observa-se a quantidade de artigos submetidos no último triênio (2011/2012/2013), o tempo médio entre submissão e aceitação e o tempo médio entre aceitação e publicação de artigos para a RBCDH. Há uma constante batalha para diminuir o tempo médio entre a submissão e a aceitação e/ou publicação dos artigos, para tanto, espera-se contar com a 
colaboração dos pares que fazem pesquisas nas diferentes áreas da Educação Física para revisarem artigos para esse periódico.

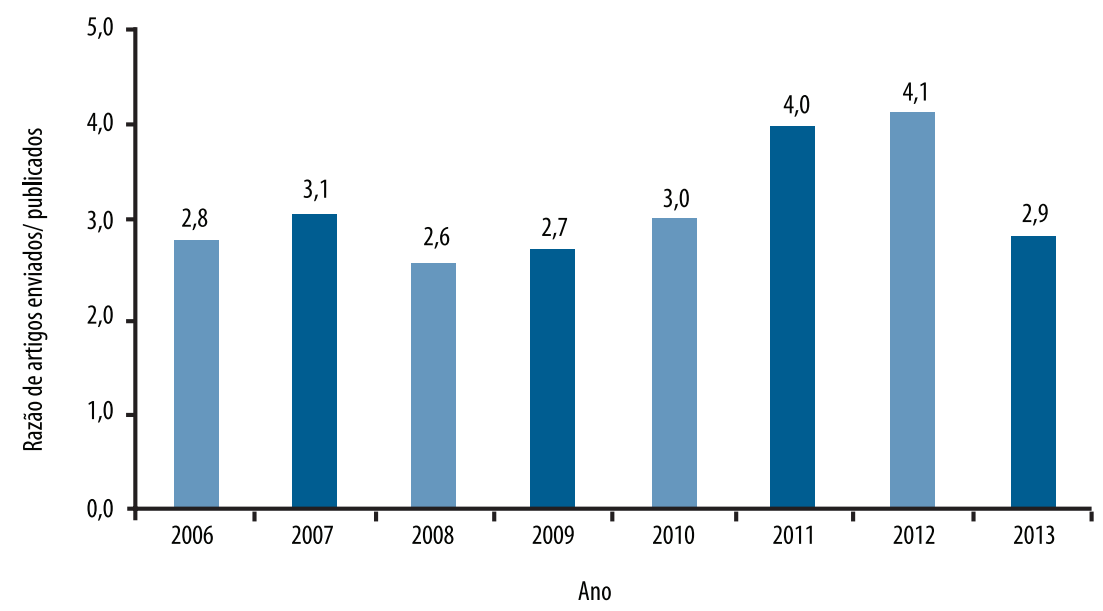

Figura 2. Razão de artigos submetidos/publicados na RBCDH de 2006 até 2013.

Tabela 1. Artigos submetidos e tempos médios (meses) entre a submissão, a aceitação e a publicação.

\begin{tabular}{lccc}
\hline ARTIGOS & 2011 & 2012 & 2013 \\
\hline Submetidos (n) & 287 & 302 & $250^{*}$ \\
Tempo médio entre submissão e aceitação (meses) & 4,9 & 5,4 & 5,4 \\
Tempo médio entre aceitação e publicação (meses) & 3,9 & 4,1 & 5,7 \\
\hline
\end{tabular}

* Submissões efetuadas até 09-12-13

Para o ano de 2014, a RBCDH continuará com a política de seriedade na relação com os autores, independente da instituição, região e temática a qual estão inseridos. O trabalho transparente com que a revista é levada será seguido nesse ano com intuito de aumentar cada vez mais o número de leitores da revista. Visando maior visibilidade internacional, a RBCDH recomenda que os artigos submetidos e aceitos para publicação sejam, de preferência, na língua inglesa. No entanto, os artigos podem ser submetidos para apreciação na língua portuguesa e espanhola. A revista poderá sofrer algumas modificações em termos de layout e editoração na forma dos artigos que serão publicados. Todas essas modificações servirão para qualificar ainda mais o periódico.

Esperamos continuar contando com o apoio dos pesquisadores brasileiros e internacionais no sentido de revisarem artigos submetidos à $\mathrm{RBCDH}$ para que cada vez mais aumente a qualidade das pesquisas publicadas. Ademais, espera-se que mais pesquisadores submetam trabalhos ao periódico e se interessem ainda mais pelos conteúdos publicados nessa revista. 